\title{
Femoral fracture following knee ligament reconstruction surgery due to an unpredictable complication of bioabsorbable screw fixation: a case report and review of literature
}

\author{
Sujith Konan · Fares Sami Haddad
}

Received: 24 May 2009/ Accepted: 17 November 2009/Published online: 17 December 2009

(C) Springer-Verlag 2009

\begin{abstract}
We report an unusual case of femoral fracture from minimal trauma, due to the rapid disappearance of a bioabsorbable interference screw used for reconstruction of the posterolateral corner of the knee. The literature on bone tunnel fractures following knee ligament reconstruction surgery is also reviewed.
\end{abstract}

Keywords Bone tunnel fracture - Bioabsorbable screws . Ligament reconstruction Adverse effects

\section{Introduction}

Interference screws used for knee ligament reconstructive surgery are a popular application of bioabsorbable materials in orthopedics. They offer various advantages $[1,2]$ over traditional metallic implants, such as the ability to engineer them to provide an optimum degradation profile, a reduced need for implant removal, and less distortion on magnetic resonance imaging (MRI).

Polylactide carbonate (PLC) is a combination of an amorphous bioabsorbable polymer, poly DL-lactide-coglycolide (PDLG), with calcium carbonate, a bone-stimulating material and neutralizing agent [3]. PLC was used to develop the "Calaxo" (Smith \& Nephew, Andover, MA, USA) interference screw for knee ligament reconstruction surgery.

S. Konan $(\bowtie) \cdot$ F. S. Haddad

Department of Trauma and Orthopaedics,

University College Hospital, London WC1E 5DB, UK

e-mail: docsujith@yahoo.co.uk

\section{Case report}

Consent was obtained from the patient to publish his case. A 26-year-old man underwent arthroscopic reconstruction of his anterior cruciate ligament (ACL), posterior cruciate ligament (PCL) and posterolateral corner following a multiple-ligament knee injury obtained while playing rugby. The patient had undergone a twisting knee injury during a tackle and was immediately diagnosed as having a severe knee injury and referred to the senior author (FSH). An MRI scan performed within twenty-four hours of the injury confirmed a tear of the ACL, PCL and posterolateral corner.

Surgical technique of ligament reconstruction

For ACL reconstruction, two semitendinosus allografts were used to fashion a four-strand $10 \mathrm{~mm}$-thick graft which was fixed with an endoloop (Smith \& Nephew) on the femoral side and a $9 \mathrm{~mm}$ by $25 \mathrm{~mm}$ PLC (Calaxo, Smith \& Nephew) interference screw on the tibial side. For the PCL reconstruction, an Achilles tendon allograft was fixed to the femoral side by a $9 \mathrm{~mm}$ by $25 \mathrm{~mm}$ PLC (Calaxo, Smith \& Nephew) screw and to the tibial side by a $9 \mathrm{~mm}$ by $35 \mathrm{~mm}$ PLLA (RCI, Smith \& Nephew) screw. For the reconstruction of the posterolateral corner of the knee, two semitendinosus allografts were passed: one into an anterior-to-posterior through-and-through hole in the fibula, and the other through an anteroposterior tunnel in the tibia adjacent to the fibula. The tibial end of the graft was fixed with an $8 \mathrm{~mm}$ by $25 \mathrm{~mm}$ PLC (Calaxo, Smith \& Nephew). The two free ends of the fibular allograft and one free end of the tibial allograft were then passed subfascially and fixed into a $9 \mathrm{~mm}$ tunnel drilled at an isometric point above the lateral epicondyle of the femur. The allograft was then fixed in the femoral tunnel 
Fig. 1 Immediate postoperative plain radiographs with illustration of tunnel positions on the lateral femoral condyle illustrated on the AP view. The lateral tunnel is placed in a more anterior plane in relation to the ACL tunnel


using a $10 \mathrm{~mm}$ by $35 \mathrm{~mm}$ PLC (Calaxo, Smith \& Nephew) screw. An image intensifier was used to guide the positioning of each screw. Meticulous care was taken to ensure that, when bone tunnels were adjacent, they were placed such that no compromise to bone strength would occur (see postoperative radiographs-Fig. 1). Excellent knee stability was noted on the table.

Postoperatively the patient was mobilized nonweightbearing for 2 months in a knee brace, and specialist physiotherapy was initiated for muscle strengthening and range of movements. After 2 months he was allowed to weight-bear. His brace was removed after 16 weeks.

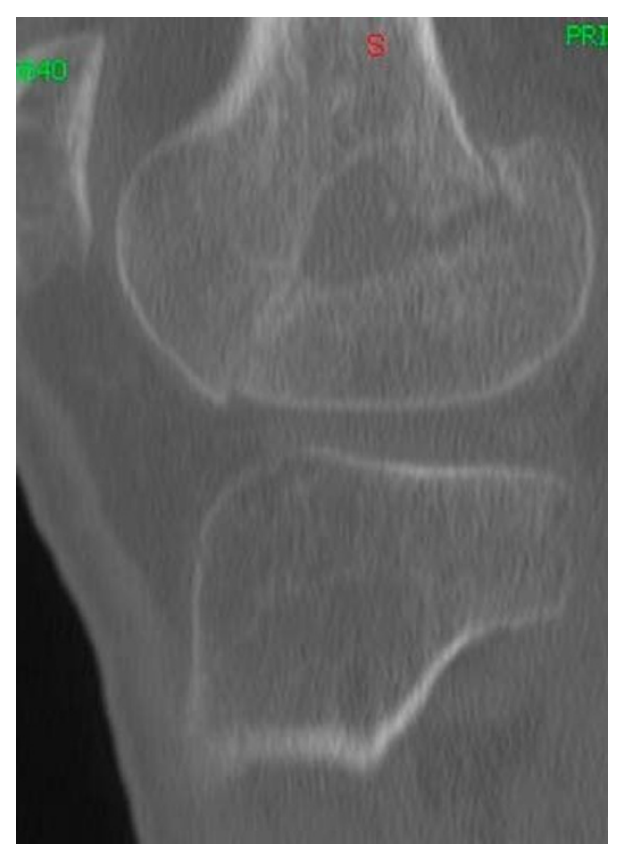

Fig. 2 CT image of the fracture in the femoral tunnel. Note the absence of the bioabsorbable screw
The immediate postoperative recovery was unremarkable and the patient made satisfactory progress with regards to rehabilitation. Six months after the procedure, the patient presented with sudden onset of knee pain after minor trauma that involved slipping but not falling in a changing room. There was no preceding trauma. On a computed tomography scan (CT-Fig. 2), the femoral fixation screw [10 $\mathrm{mm}$ by $35 \mathrm{~mm}$ PLC (Calaxo, Smith \& Nephew)] of the posterolateral corner allograft was found to be completely degraded, and a minimally displaced fracture was noted through the tunnel (Fig. 3). No bone regeneration was noted in the tunnel. As knee stability was not compromised, the patient was managed conservatively by immobilization in a brace for six weeks. The recovery was satisfactory, with a return to premorbid function by approximately 14 months after surgery (see weight-bearing radiographs-Fig. 4). At 24 months of follow-up, the patient continues to have very good functional results, with bilaterally equal range of movements in the knee. Clinical examination using Lachman's test, the drawer test and the collateral stress test have confirmed a stable knee joint.

\section{Discussion}

The main disadvantages associated with the use of bioabsorbable implants are their comparatively low mechanical strength, their relatively high cost, and the undesirable biological response [1] they may produce. The persistence of bioabsorbable screws for up to 3 years after their insertion is well documented in MRI studies after knee ligament reconstruction surgery [4-6].

In ovine models [3], the PLC screws have shown gradual and controlled degradation, stimulating ossification of the graft within the bone tunnel. New bone thus formed 
Fig. 3 Plain radiographs showing the minimally displaced fracture. Please note the "empty tunnels" on the rotation views
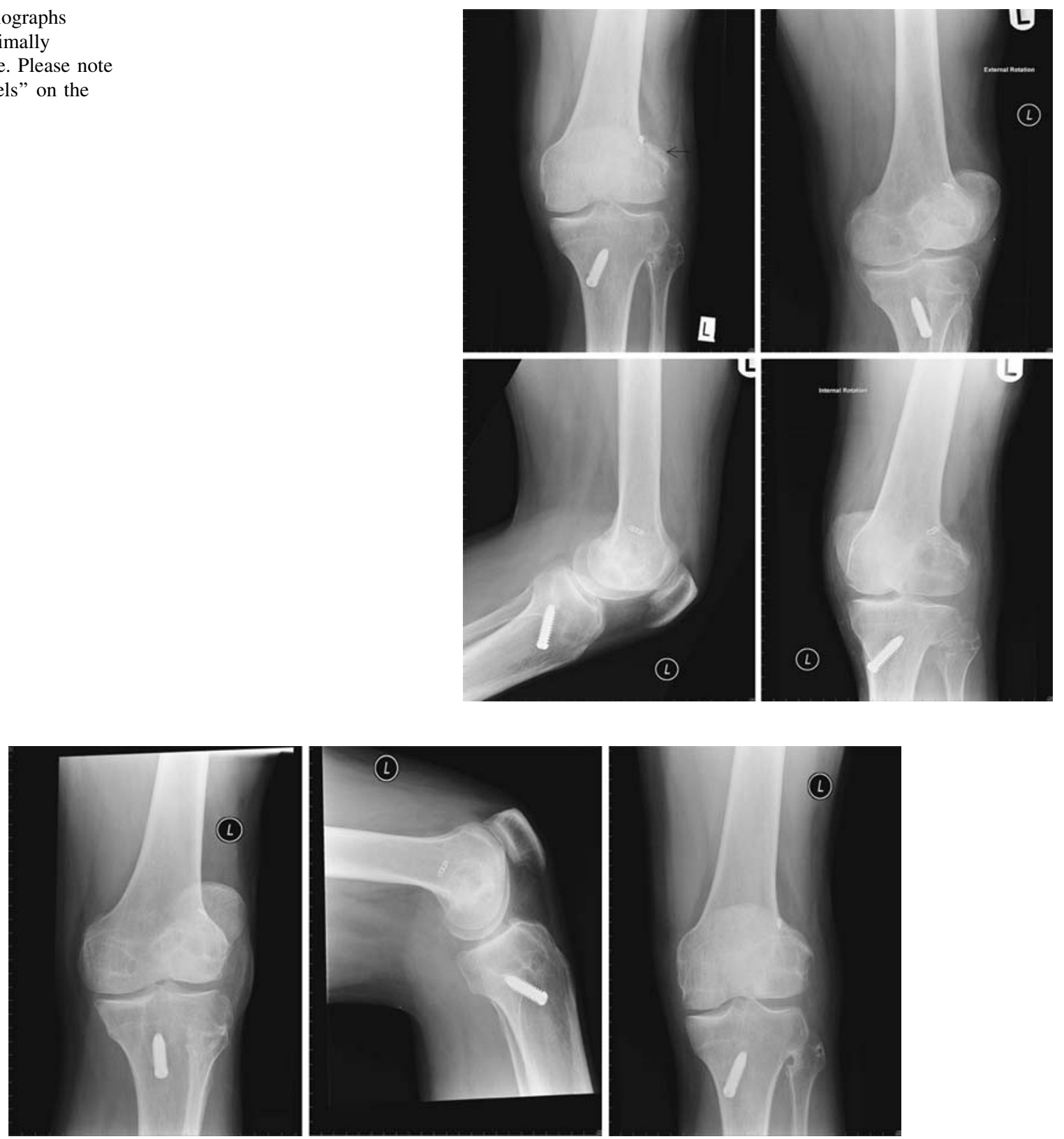

Fig. 4 Plain radiographs taken at 14 months suggest a healed fracture

was noted around the margin of the screw as early as 6-12 weeks. This was followed by partial integration of the screw with bone by 26 weeks and complete replacement with new bone at 52 weeks. Computed tomography data followed this pattern, with extensive integration of the screw to bone by 26 weeks and disappearance of the screw by 52 weeks. An interference screw that would replenish the bone tunnel would be an ideal choice for knee ligament reconstruction surgery. However, clinical studies looking at the outcome of PLC screws are lacking.

There are few reports of femoral fractures at the sites of graft fixation associated with ACL reconstruction
(Table 1). Noah et al. [7] in 1992 and Radler et al. [8] in 2000 reported an extracondylar femur fracture at the site of extra-articular augmentation of ACL reconstruction. In the former case, the fracture occurred 6 months after an iliotibial band augmentation of a patellar tendon graft ACL reconstruction, whereas the latter case followed 20 months after the removal of a lateral augmentation device used in an ACL reinsertion.

In the case reported by Manketelow et al. [9] in 1998, the fracture extended from the staple of the extra-articular augmentation to the intraosseous tunnel, 24 months after a hamstring autograft ACL reconstruction with extra- 
Table 1 Femur fracture

\begin{tabular}{|c|c|c|c|}
\hline Author & Procedure & Fixation & Time from procedure \\
\hline Noah et al. [7] & $\begin{array}{l}\text { Patellar tendon ACL reconstruction and } \\
\text { ITB extra-articular tenodesis }\end{array}$ & Interference screw & 6 months \\
\hline Ternes et al. [10] & GORE-TEX graft ACL revision & N/A & 8 weeks \\
\hline Wiener and Siliski [11] & Patellar tendon ACL revision & & 7 months \\
\hline Manktelow et al. [9] & $\begin{array}{l}\text { Hamstring tendon ACL reconstruction } \\
\text { with extra-articular tenodesis }\end{array}$ & & $\begin{array}{l}24 \text { months fracture from staple } \\
\text { of extra-articular } \\
\text { augmentation to intraosseous tunnel }\end{array}$ \\
\hline Berg et al. [13] & BPTB ACL reconstruction & & 8 weeks \\
\hline Radler et al. [8] & $\begin{array}{l}\text { ACL reinsertion and LAD. Latter } \\
\text { removed after } 5 \text { months }\end{array}$ & $6.5 \mathrm{~mm}$ cancellous screw & 20 months \\
\hline Mithoefer et al. [14] & Patellar tendon ACL reconstruction & $\begin{array}{l}7 \times 25 \text { metal interference } \\
\text { screw for a } 10 \mathrm{~mm} \text { tunnel }\end{array}$ & 5 months. Fall and hyperextension injury \\
\hline Wilson et al. [15] & BPTB ACL reconstruction & Interference screw, ? size & 9 months, fall \\
\hline Sheps et al. [12] & $\begin{array}{l}\text { Quadrupled ST-G autograft ACL } \\
\text { reconstruction }\end{array}$ & Endoloop button & 5 months, head injury, ? fall \\
\hline
\end{tabular}

Table 2 Tibial plateau fracture

\begin{tabular}{|c|c|c|c|}
\hline Author & Procedure & Fixation & Time \\
\hline El-Hage et al. [16] & Achilles tendon ACL reconstruction & Richards interference screw & 18 months post-trauma \\
\hline Morgan and Steensen [17] & ACL reconstruction & & \\
\hline Delcogliano et al. [18] & Patellar tendon ACL reconstruction & $\begin{array}{l}10 \mathrm{~mm} \text { tibial tunnel and } \\
9 \times 25 \text { interference screws }\end{array}$ & 7 months \\
\hline Mithofer et al. [19] & BPTB ACL reconstruction & Post and washer & $\begin{array}{l}7 \text { months. Fall down stairs and } \\
\text { twisting knee injury }\end{array}$ \\
\hline Sundaram et al. [20] & ACL reconstruction & $\begin{array}{l}8 \mathrm{~mm} \text { tunnel fixed with } \\
9 \times 25 \mathrm{RCI} \text { screws }\end{array}$ & 12 months, fall \\
\hline Thaunat et al. [21] & ACL reconstruction & $\begin{array}{l}11 \mathrm{~mm} \text { tunnel, } 9 \mathrm{~mm} \text { PGA- } \\
\text { co-TMC screw }\end{array}$ & $\begin{array}{l}4 \text { years, valgus compression } \\
\text { injury after fall }\end{array}$ \\
\hline
\end{tabular}

articular tenodesis. In a case reported by Ternes et al. [10] in 1993, the femoral tunnel used for the placement of a GORE-TEX prosthetic graft was the site of the fracture, which occurred 8 weeks following the procedure. Multiple anterolateral femoral cortex perforations were reported as the etiology for the fracture reported 7 months following a patellar tendon ACL reconstruction by Weiner et al. [11] in 1996, and 5 months following quadrupled hamstring graft ACL reconstruction by Sheps et al. [12] in 2006. Berg et al. [13] in 1999 reported a fracture through the femoral tunnel 8 weeks after a bone-patellar tendon-bone ACL reconstruction. At the time of the operation, the femoral tunnel had been over-drilled and the cortex had been perforated. The femoral tunnel was itself noted to be the stress riser, precipitating a fracture 5 months following patellar tendon ACL reconstruction by Mithoefer et al. [14] in 2005, and 9 months following a similar procedure by Wilson et al. [15] in the same year.
Cases of tibial plateau fracture through the distal fixation site of the ACL grafts have also been reported [16-21] (Table 2). In the case reported by Thaunat et al. [21] in 2006, a $9 \mathrm{~mm}$ bioabsorbable screw (polyglycolide-co-trimethylenecarbonate, Endofix, Mansfield, MA, USA) was used to fix the tibial end of a bone patellar tendon bone ACL reconstruction. Four years later the patient presented with tibial plateau fracture following a valgus compression trauma to his knee. Imaging demonstrated screw resorption and tunnel enlargement.

Biomechanical studies have shown that a bone defect such as a screw hole can concentrate stress and decrease the bone strength to torsional loading [22-24]. This may explain the fractures noted in the osseous tunnels following knee ligament reconstruction surgery.

Both mechanical and biological factors have been recognized to contribute to tunnel enlargement after ACL reconstruction [25]. Mechanical factors include motion of 
the graft within the tunnel, fixation methods/devices, stress shielding of the graft, improper graft placement, and accelerated rehabilitation. Graft swelling, the use of allograft tissue, synovial fluid propagation within bony tunnels, and increased cytokine levels within the knee are all biologic modes of osteolysis contributing to tunnel enlargement. In most cases tunnel enlargement is minimal after 3 months [25]. Unpredictable bioabsorbable screw resorption results in graft in empty tunnel and perhaps synovial reaction and cytokines, all contributing to persistent tunnel enlargement and bone weakening.

In our case, rapid degradation of the PLC screws in the osseous tunnel in the absence of any attempted bone integration may have predisposed to the fracture by a similar mechanism. Ongoing clinical concerns with the unpredictable absorption of the PLC screws (Calaxo, Smith \& Nephew) lead to their withdrawal from the market in 2007. It is crucial to be aware of adverse effects where this particular interference screw has been used.

In conclusion, stress risers may occur following the use of bioabsorbable screws for ligament reconstruction surgery, particularly if screw resorption is rapid and bone integration is not complete.

Femoral fracture presenting as a late complication following the use of bioabsorbable interference screws in knee ligament reconstruction surgery is rare. It is important to be aware of this potential postoperative complication when considering which form of screw fixation to use.

Conflict of interest statement No conflicts of interests or disclosures.

\section{References}

1. Südkamp NP, Kääb MJ (2002) Biodegradable implants in soft tissue refixation: experimental evaluation, clinical experience, and future needs. Injury 33(Suppl 2):B17-B24

2. Ambrose CG, Clanton TO (2004) Bioabsorbable implants: review of clinical experience in orthopedic surgery. Ann Biomed Eng 32(1):171-177

3. Walsh WR, Cotton NJ, Stephens P, Brunelle JE, Langdown A, Auld J, Vizesi F, Bruce W (2007) Comparison of poly-L-lactide and polylactide carbonate interference screws in an ovine anterior cruciate ligament reconstruction model. Arthroscopy 23(7):757$765765 . \mathrm{e} 1-2$

4. Drogset JO, Grøntvedt T, Myhr G (2006) Magnetic resonance imaging analysis of bioabsorbable interference screws used for fixation of bone-patellar tendon-bone autografts in endoscopic reconstruction of the anterior cruciate ligament. Am J Sports Med 34(7):1164-1169

5. Gawęda K, Walawski J, Węgłowski R, Krzyżanowski W (2009) Comparison of bioabsorbable interference screws and posts for distal fixation in anterior cruciate ligament reconstruction. Int Orthop 33(1):123-7
6. Fink C, Benedetto KP, Hackl W, Hoser C, Freund MC, Rieger M (2000) Bioabsorbable polyglyconate interference screw fixation in anterior cruciate ligament reconstruction: a prospective computed tomography-controlled study. Arthroscopy 16(5):491-498

7. Noah J, Sherman OH, Roberts C (1992) Fracture of the supracondylar femur after anterior cruciate ligament reconstruction using patellar tendon and iliotibial band tenodesis. A case report. Am J Sports Med 20:615-618

8. Radler C, Wozasek GE, Seitz H, Vecsei V (2000) Distal femoral fracture through the screw hole of a ligament augmentation device fixation. Arthroscopy 16:737-739

9. Manktelow AR, Haddad FS, Goddard NJ (1998) Late lateral femoral condyle fracture after anterior cruciate ligament reconstruction: a case report. Am J Sports Med 26:587-590

10. Ternes JP, Blasier RB, Alexander AH (1993) Fracture of the femur after anterior cruciate ligament reconstruction with a GoreTex prosthetic graft. A case report. Am J Sports Med 21:147-149

11. Wiener DF, Siliski JM (1996) Distal femoral shaft fracture: a complication of endoscopic anterior cruciate ligament reconstruction: a case report. Am J Sports Med 24:244-247

12. Sheps DM, Reed JG, Hildebrand KA, Hiemstra LA (2006) Supracondylar femur fracture after endoscopic anterior cruciate reconstruction using an Endobutton. Clin J Sport Med 16:428429

13. Berg EE (1994) Lateral femoral condyle fracture after endoscopic anterior cruciate ligament reconstruction. Arthroscopy 10:693695

14. Mithofer K, Gill TJ, Vrahas MS (2005) Supracondylar femoral fracture after arthroscopic reconstruction of the anterior cruciate ligament. J Bone Joint Surg 87(7):1591-1596

15. Wilson TC, Rosenblum WJ, Johnson DL (2004) Fracture of the femoral tunnel after an anterior cruciate ligament reconstruction. Arthroscopy 20:e45-e47

16. El-Hage ZM, Mohammed A, Griffiths D, Richardson JB (1998) Tibial plateau fracture following allograft (ACL) reconstruction. Injury 29(1):73-74

17. Morgan E, Steensen RN (1998) Traumatic proximal tibial fracture following anterior cruciate ligament reconstruction. Am J Knee Surg 11(3):193-194

18. Delcogliano A, Chiossi S, Caporaso A, Franzese S, Menghi A (2001) Tibial plateau fracture after arthroscopic anterior cruciate ligament reconstruction. Arthroscopy 17(4):E16

19. Mithofer K, Gill TJ, Vrahas MS (2004) Tibial plateau fracture following anterior cruciate ligament reconstruction. Knee Surg Sports Traumatol Arthrosc 12(4):325-328

20. Sundaram RO, Cohen D, Barton-Hanson N (2006) Tibial plateau fracture following gracilis-semitendinosus anterior cruciate ligament reconstruction: the tibial tunnel stress-riser. Knee 13:238240

21. Thaunat M, Nourissat G, Gaudin P, Beaufils P (2006) Tibial plateau fracture after anterior cruciate ligament reconstruction: role of the interference screw resorption in the stress riser effect. Knee 13:241-243

22. Burstein AH, Currey J, Frankel VH et al (1972) Bone strength: the effect of screw holes. J Bone Joint Surg Am 54:1143-1156

23. Brooks DB, Burstein AH, Frankel VH (1970) The biomechanics of torsional fractures: the stress concentration effect of a drill hole. J Bone Joint Surg Am 52:507-514

24. Juliano PJ, Yu JR, Schneider DJ, Jacobs CR (1997) Evaluation of fracture predilection in the calcaneus after external fixator pin removal. J Orthop Trauma 11:430-434

25. Wilson TC, Kantaras A, Atay A, Johnson DL (2004) Tunnel enlargement after anterior cruciate ligament surgery. Am J Sports Med 32(2):543-548 